Korkmaz,S. Bel Hadl Ali, N. and Smith, I.F.C. "Configuration of control system for damage tolerance of a tensegrity bridge" Advanced Engineering Informatics, 26, 2012, pp 145-155 doi:10.1016/j.aei.2011.10.002

\title{
Configuration of Control System for Damage Tolerance of a Tensegrity Bridge
}

\author{
Sinan Korkmaz ${ }^{1}$, Nizar Bel Hadj Ali ${ }^{2}$ and lan F.C. Smith ${ }^{1 *}$ \\ 1 - Applied Computing and Mechanics Laboratory \\ School of Architecture, Civil and Environmental Engineering (ENAC) \\ Swiss Federal Institute of Technology, Lausanne (EPFL) \\ ENAC/IIC/IMAC, Station 18, 1015 Lausanne, Switzerland \\ 2 - Applied Mechanics and Systems Research Laboratory \\ Ecole Polytechnique de Tunisie, University of Carthage \\ B.P. 743, La Marsa 2078, Tunisia \\ *Corresponding Author, Phone: +41 2169352 42; Fax: +41 2169347 48; Email: \\ ian.smith@epfl.ch
}

\begin{abstract}
Tensegrity structures are spatial, discrete and lightweight structures that are composed of struts in compression and pre-stressed cables. Stability is provided by the self-stress state between elements independently of external actions. Tensegrity structures are attractive due to their potential for deployability, ease of tuning and high precision control. Since tensegrity structures have highly coupled behavior, placement of actuators is a primary concern when designing active control systems. This study investigates the active control performance of cable members of a tensegrity bridge. The actuation efficiencies of cable members are evaluated through a multi-criteria approach. The configuration of the control system is thus identified through outranking candidate active members. A multi-objective damage tolerance strategy is then proposed and optimally directed control solutions are identified using stochastic search. Case studies for several damage scenarios are examined to validate results. The most efficient active cable configuration is compared with that needed for deployment. This study is divided into two phases. After the description of a $16 \mathrm{~m}$-span tensegrity bridge, optimally directed locations of active cables are determined in the first phase. Secondly, a procedure to ensure damage tolerance of the structure is proposed. The multi-objective self-repair procedure provides damage tolerance minimizing both maximum deflections in the structure and stresses in the structural members. Results indicate that the control strategy for deployment is a near-optimal solution for damage tolerance. The proposed methodology is applicable to a range of complex active structures.
\end{abstract}

Keywords: structural control, optimum active control, control efficiency, damage tolerance, Pareto optimum, multi-criteria decision making, multi-objective optimization 
Korkmaz,S. Bel Hadl Ali, N. and Smith, I.F.C. "Configuration of control system for damage tolerance of a tensegrity bridge" Advanced Engineering Informatics, 26, 2012, pp 145-155 doi:10.1016/j.aei.2011.10.002

\section{Introduction}

Advances in theory and practice are changing the ways engineers perceive structures. Due to incorporated intelligence, structures can become dynamic objects capable of interacting with complex environments [1]. This induced a growing interest in structural control in the past decade. While aerospace engineers have used active motion control of large space structures for many years, active control of civil structures is an emerging area. Although the basics of active control are similar in both fields, its application to civil structures presents new challenges that must be addressed in order to benefit from the potential of active control technology [2].

Active control of civil structures was first introduced by Yao [3] as a means of protecting tall buildings against high winds However, in the case of actively controlled civil structures, longterm reliability of control systems has been a matter of controversy. This is mainly due to large return periods associated with strong external loading, such as those induced by earthquakes and windstorms. Instead, actively controlled structures are more suited to satisfy serviceability criteria (deflections, vibrations, etc.) in changing environments.

The aim of active control is to enhance structural performance by sensing the changes in behavior and in loading, adapting the structure to meet goals, and retrieving past events to improve future performance [4]. Regarding these criteria, the tensegrity concept is particularly suited to actively controlled structures [5]. Tensegrities are spatial, discrete and lightweight structures that are composed of struts in compression and pre-stressed cables. Deployability, ease of tuning and high precision control have encouraged research into active control of tensegrity structures. An overview of active control of tensegrity systems is available in [6].

Active control of tensegrity structures has been studied since the mid-1990s. Djouadi et al. [7] developed an active control strategy for vibration damping of a tensegrity structure. Sultan [8] investigated tendon-control reconfiguration of simple tensegrity modules. Kanchanasaratool and Williamson [9] used actuated struts to perform feedback shape control of a general class of tensegrity structures. Wijdeven and De Jager [10] proposed an optimized reference trajectory for shape changes of an arbitrary tensegrity structure. Fest et al. [11] experimentally explored shape control of a five-module large-scale active tensegrity structure. Active control was performed through contracting and elongating active struts in order to ensure serviceability of the structure when it was subjected to additional loads $[12,13]$. Active control was extended to multi-objective control, self-diagnosis and self-repair in situations of cable damage and vibration damping [14-16]. Although active control has been applied on tensegrity structures in these studies, none of them carried out an optimization of actuator locations taking into account both stresses and deflections.

Tensegrity structures are prone to difficulties associated with meeting serviceability criteria when they are utilized as civil structures. Damage tolerance of tensegrity structures is an important research area since structural integrity is achieved through self-stress. Few studies on this aspect of control can be found in literature. Ben Kahla and Moussa [17] numerically studied effect of sudden rupture of a cable component in a tensegrity assemblage using nonlinear 
Korkmaz,S. Bel Hadl Ali, N. and Smith, I.F.C. "Configuration of control system for damage tolerance of a tensegrity bridge" Advanced Engineering Informatics, 26, 2012, pp 145-155 doi:10.1016/j.aei.2011.10.002

dynamic time history analysis. Adam and Smith [15] experimentally investigated damage locations in situations of partially defined damage and proposed measures for self-repair of an active tensegrity structure. Abedi and Shekastehband [18] addressed the structural integrity of a double layer tensegrity grid subject to member loss.

Efficiently providing damage tolerance to structures requires optimization of actuator locations. Selection of locations where the actuators are to be installed in the structure calls for multiobjective optimization. Recent advances in multi-objective optimization resulted in reliable techniques for generating nondominated solutions. Evolutionary techniques are currently used in various fields due to their effectiveness and robustness in searching for a set of trade-off solutions [19]. However, the selection of the "best solution" to be adopted among the Pareto optimal set is a challenge.

Several decision support systems have recently been proposed to help in the selection of the best compromise alternatives. Major approaches to Multi-Criteria Decision Making (MCDM) include multi-attribute utility theory and outranking methods [20].

Grierson [21] proposed an MCDM strategy employing a tradeoff-analysis technique to identify compromise designs for which the competing criteria are mutually satisfied in a Pareto optimal set. Preference Ranking Organization Method for Enrichment Evaluation (PROMETHEE) is an alternative method to rank solutions in a Pareto set $[22,23]$. PROMETHEE was proposed as an MCDM method to solve discrete decision problems with conflicting criteria. Although there are many studies that employ the Pareto optimum concept for various purposes, none of them applies MCDM strategies to the selection of actuator locations.

This study investigates active control ability of cable members of a tensegrity bridge for damage tolerance purposes in two phases. Cable damage is simulated by taking cable members out of the structural analysis model. The research builds upon previous work by Korkmaz et al. [24] on damage tolerance of a tensegrity structure.

In the first phase, an evaluation of the effects of actuation on maximum deflections and stresses in structural members is carried out. Multi-objective optimization of actuator locations on a tensegrity structure is studied. Each cable's actuation efficiency in the tensegrity bridge are compared. Pareto filtering is applied to identify the most efficient cables. Results are compared to outcomes of two MCDM selection strategies.

In the second phase, case studies for several damage scenarios are examined to validate results. Multi-objective stochastic search is used to identify optimally directed control solutions enabling adaptation of structural response to acceptable levels at minimum control effort. Moreover, the best active control configuration used for damage tolerance is compared to that required for deployment of the bridge. 
Korkmaz,S. Bel Hadl Ali, N. and Smith, I.F.C. "Configuration of control system for damage tolerance of a tensegrity bridge" Advanced Engineering Informatics, 26, 2012, pp 145-155 doi:10.1016/j.aei.2011.10.002

\section{Design characteristics of the tensegrity bridge}

An elevation view of the tensegrity bridge is given in Figure 1. The bridge is composed of four ring-shaped tensegrity modules spanning $16 \mathrm{~m}$ [25]. Symmetry about midspan is obtained by mirroring two modules. The structure is designed to have $2.5 \mathrm{~m}$ width internal space for walking and a clearance of $2.5 \mathrm{~m}$ as recommended by codes [26]. The dimensions of the free space are fixed to have enough room for non-motorized traffic (pedestrians and cyclists). The nodes of the bridge structure at both extremities are attached to a steel frame which is rigidly anchored to the ground (Figure 1). The footbridge deck is connected to four base nodes at each module. Although this study focuses on this configuration, the bridge is intended to be deployable from both supports, meeting in the middle.

The pentagon module contains 15 nodes describing 3 pentagonal layers (Figure 2). The middle pentagonal-layer nodes are rotated with respect to outer pentagon by $36^{\circ}$ in the counterclockwise direction [27]. The pentagon module is made up of 15 struts held together in space by 30 cables forming a ring-shaped tensegrity unit. Struts are categorized into diagonal and intermediate struts based on their position. Diagonal struts connect outer and inner pentagon nodes while intermediate struts connect middle pentagon nodes to outer and inner pentagon nodes. Similarly, cables are separated into 10 layer cables and 20 x-cables. Layer cables connect nodes of the two outer pentagons while $x$-cables connect middle pentagon nodes to inner and outer pentagon nodes. The $10 \mathrm{x}$-cables that are coplanar with the diagonal struts are called coplanar x-cables.

Figure 1. Tensegrity bridge (thick lines denote bars while thin lines denote cables)

The pentagon module used in this study spans $400 \mathrm{~cm}$ with an inner radius of $312 \mathrm{~cm}$. This geometry satisfies internal space requirements. Diagonal and intermediate struts are chosen to have the same length of $542 \mathrm{~cm}$. Layer cables have a length of $366 \mathrm{~cm}$ while $x$-cables are $277 \mathrm{~cm}$ long. The nodes of the structure at both extremities are fixed in all three translation directions. Live loads are applied on the footbridge deck and are thus transmitted to the four bottom nodes on each module. Dead load is also applied as nodal forces on the structure.

Figure 2. Pentagon module (thick lines denote bars while thin lines denote cables)

Each sequence of four noncoplanar $\mathrm{x}$-cables is replaced by a single continuous cable that is assumed to run over frictionless pulleys connected to the nodes. The 40 noncoplanar $x$-cables of the tensegrity bridge are thus replaced by ten continuous cables. A layout of continuous cables is given in Figure 7 (b).

Design optimization of the tensegrity bridge is performed using member dimensions and selfstress level as design variables following a procedure described in Bel Hadj Ali et al. [28]. Struts 
Korkmaz,S. Bel Hadl Ali, N. and Smith, I.F.C. "Configuration of control system for damage tolerance of a tensegrity bridge" Advanced Engineering Informatics, 26, 2012, pp 145-155 doi:10.1016/j.aei.2011.10.002

are separated into two design groups: diagonal and intermediate struts. Strut members in each group are to have the same hollow tube section profile. Layer cables in the whole footbridge are specified to be of same section and experience the same level of self-stress. The same design decision is taken into account for $\mathrm{x}$-cables.

As recommended by the Swiss Code, a live load of $4 \mathrm{kN} / \mathrm{m}^{2}$ is taken into account [29]. The pedestrian walking surface is assumed to have a weight of $1 \mathrm{kN} / \mathrm{m}^{2}$. The structure members are selected from commercially available standard steel sections with specified cross-sectional profiles and cables. For struts, the product set consists of 45 hollow-tube section profiles. The steel grade is S355, with a modulus of elasticity of 210GPa and yield stress of 355MPa. For cables, a list of 22 sections is used. Cables are made of stainless steel with a modulus of elasticity of $120 \mathrm{GPa}$. Yield limit of the cables is assumed to be $1069 \mathrm{MPa}$. Euler buckling stress defines the stress limit of the struts.

Structural analyses for various load combinations are performed using a modified dynamic relaxation algorithm that accommodates continuous cables [30]. Analysis results are used to check safety and serviceability requirements. A genetic algorithm (GA) is employed to solve the design optimization task. Optimization variables are coded as integer strings. Penalty functions are employed to handle design constraints by penalizing individuals that violate constraints, and thus giving them a lower probability of survival. The penalty function approach is implemented by adding an additional term to the objective function. This additional term corresponds to the cost of violating constraints. In this manner, the search for optimum solutions is directed toward feasible regions of the search space. For the design task, optimization results are satisfactory for a population size of 50 individuals running for 60 generations. Crossover and mutation probabilities are fixed as 0.9 and 0.1 , respectively. The best solution generated over a sequence of five runs using different random seeds is taken to be the optimal design solution.

Table 1 gives the member sections and self-stress ratios for structural members. The self-stress ratios given in Table 1 are calculated as the ratio between the member pretension axial force and its resistance axial force. For the designed configuration, the maximum midspan deflection under the serviceability limit state (SLS) load combination is $2.7 \mathrm{~cm}$, which verifies the SIA Code limitation (span length/600). Under ultimate limit state (ULS) load combinations, a maximum axial compression force of $30.4 \mathrm{kN}$ is obtained in intermediate struts and this represents $35 \%$ of buckling capacity. Diagonal struts bear a maximum compression force of $65.4 \mathrm{kN}$ representing $53 \%$ of their buckling capacity. Maximum tension forces of $71.4 \mathrm{kN}$ and $46.4 \mathrm{kN}$ are obtained for $\mathrm{x}$-cables and layer cables respectively. Tension forces in $\mathrm{x}$-cables and layer cables represent $70 \%$ and $68 \%$ of their tension capacities respectively.

The envisaged actuation system consists of 10 motors and a computer system to carry out active control commands. This technology is currently available on the market. The effect of friction is expected to increase the safety and serviceability of the bridge with a small margin. Although it is expected increase control energy, the effects of friction in the pulleys is out of the scope of this study. 
Korkmaz,S. Bel Hadl Ali, N. and Smith, I.F.C. "Configuration of control system for damage tolerance of a tensegrity bridge" Advanced Engineering Informatics, 26, 2012, pp 145-155 doi:10.1016/j.aei.2011.10.002

Table 1. Design results for the bridge

\begin{tabular}{lcccc}
\hline Member & $\begin{array}{c}\text { Diameter } \\
{[\mathrm{mm}]}\end{array}$ & $\begin{array}{c}\text { Cross- } \\
\text { Sectional Area } \\
{\left[\mathrm{mm}^{2}\right]}\end{array}$ & $\begin{array}{c}\text { Self-Stress Ratio } \\
{[\%]}\end{array}$ & $\begin{array}{c}\text { Load-Carrying } \\
\text { Capacity of } \\
\text { Members [kN] }\end{array}$ \\
\hline Diagonal struts & 114.3 & 1390 & - & 124 \\
Intermediate struts & 101.6 & 1230 & - & 87 \\
Layer cables & 9 & 63.6 & 17.5 & 68 \\
X-cables & 11 & 95.03 & 17.5 & 102 \\
\hline
\end{tabular}

\section{Efficiency of actuation}

A robust approach for active member selection should take into account both deflection and stress criteria. Two indices are thus defined: the first index is deflection-based and is intended to measure the effect of actuating cable on mid-span deflection of the bridge. The second index is intended to reflect the level of disturbance into stresses caused by a cable actuation. Details related to these two indices are given in the next two sub-sections. Since numerical simulations show that the tensegrity bridge is damage tolerant with respect to safety requirements, the objective of active control is to meet serviceability requirements.

65 damage cases are taken into account. Damage is simulated for 15 layer cables of the inner pentagons, 40 coplanar $\mathrm{x}$-cables and 10 noncoplanar $\mathrm{x}$-cables. Recall that each noncoplanar $\mathrm{x}$ cable is a continuous cable composed of four cable-segments running over two modules. Cable damage is simulated by taking cable members out of the structural analysis model. Due to the symmetry of the bridge, actuation is studied for the cables of the first half of the bridge. Figure 3 shows cable members of the first and the second module of the bridge. Actuation is thus studied for 35 cables: 10 layer cables, 20 coplanar $x$-cables and 5 continuous noncoplanar $x$ cables. Furthermore, for each actuated cable, ten discrete values for actuation are considered running between $-5 \mathrm{~cm}$ and $+5 \mathrm{~cm}$ in steps of $1 \mathrm{~cm}$.

Maximum actuation length is limited to $5 \mathrm{~cm}$ as preliminary studies showed that this value is sufficient for damage tolerance in most single-cable damage cases. Greater maximum actuation lengths result in larger solution spaces, thus, longer computation time. Efficiency of each cable in terms of active control is determined separately. Since the actuation system is proposed to provide damage tolerance in many damage cases, the overall active control performance of each cable at each damage case is evaluated as the sum of effects at each actuation step and damage case. In spite of the nonlinear behavior associated with tensegrity structures, the combination of efficient individual cables is expected to have high overall actuation efficiency when they are actuated simultaneously.

Figure 3. Views of the tensegrity bridge with cable numbers for the two first modules 
Korkmaz,S. Bel Hadl Ali, N. and Smith, I.F.C. "Configuration of control system for damage tolerance of a tensegrity bridge" Advanced Engineering Informatics, 26, 2012, pp 145-155 doi:10.1016/j.aei.2011.10.002

\subsection{Deflection index (DI)}

For the purposes of this paper, the aim of the active control system is defined to be maintaining the serviceability of the tensegrity bridge in situations of damage. The Deflection Index (DI) shows the ability of a cable member to adapt the structure when excessive deflections arise due to damage.

First, for each cable member (c) and for each actuation value (a), damage cases $(d=1, \ldots, 65)$ are simulated and actuation is carried out. Simulation results are used to calculate the actuation efficiency $\left(A \_\right.$eff $\left.{ }_{c, a}\right)$ of cable $(c)$ when it is actuated with the value (a). Actuation efficiency is defined as the sum of the differences ( $\left(\right.$ iff $_{d, c, a}$ ) between the maximum deflection after actuation $\left(a z_{\text {max }, \mathrm{d}}\right)$ and the maximum deflection in the damaged structure before actuation $\left(\mathrm{d} \mathrm{z}_{\mathrm{max}, \mathrm{d}}\right)$. This difference is computed and absolute values are divided by the maximum allowed deflections at bridge midspan $\left(z_{\text {lim }}\right)$. If actuation does not lead to a correction in the midspan deflection, the deflection difference is taken as zero (Eq. 1).

$\operatorname{Diff}_{d, c, a}=\left\{\begin{array}{c|cc}1 / z_{\lim } \cdot\left|a z_{\max , d}-d z_{\max , d}\right| & \text { if } & a z_{\max , d}>d z_{\max , d} \\ 0 & \text { if } & a z_{\max , d} \leq d z_{\max , d}\end{array}\right.$

Note that this equation is valid only when values for deflection are negative. Difference values are then averaged to calculate the actuation efficiency ( $A$ _eff $\left.f_{c, a}\right)$ as shown in Eq. 2.

$A_{-}$eff $f_{c, a}=1 / 65 \sum_{d=1}^{65} \operatorname{Diff}_{d, c, a}$

Finally, to evaluate the Deflection Index (DI) for cable (c), actuation efficiencies obtained for actuation values running between $-5 \mathrm{~cm}$ and $+5 \mathrm{~cm}$ are summed-up (Eq. 3). A sum of the actuation efficiency values is calculated since the objective of the actuation system is to provide damage tolerance for cases where any of the cables is damaged.

$D I_{c}=\sum_{a=-5}^{+5} A_{-} e f f_{c, a}$

[Eq. 3]

\subsection{Stress index (SI)}

A robust approach for active control should provide the shape change that is necessary to adapt the structure with minimum changes in stresses of structural members. The stresses must be controlled not only to assure that there is no local or global collapse in the structural system but also to minimize the changes in stresses at each structural member. Therefore, the Stress Index (SI) is intended to measure to what degree, the actuation of a cable, changes stresses in the structural elements.

In order to evaluate the influence of actuating each potential active cable on the stress distribution in the tensegrity bridge, differences in stresses are obtained for each actuation value (a) and each active cable (c). Simulation results are thus used to calculate the stress efficiency $\left(S_{-}\right.$eff $\left.f_{c, a}\right)$ of cable $(c)$ when it is actuated with the value $(a)$. For each damage case $d(d$ 
Korkmaz,S. Bel Hadl Ali, N. and Smith, I.F.C. "Configuration of control system for damage tolerance of a tensegrity bridge" Advanced Engineering Informatics, 26, 2012, pp 145-155 doi:10.1016/j.aei.2011.10.002

$=1, \ldots, 65)$ the maximum difference $\left(M\right.$ iff $\left._{d}\right)$ between the stresses in each member group after actuation ( $a \mathrm{~N}_{\text {mgroup,d }}$ ) and the stresses in the same group of members of the damaged structure before actuation ( $d N_{\text {mgroup,d }}$ ) is calculated. This difference is thus calculated for four member groups (layer cables, $\mathrm{x}$-cables, intermediate struts and diagonal struts). For each group, values of ( $\left.a N_{\text {mgroup,d }}\right)$ and ( $\left.d N_{\text {mgroup,d }}\right)$ are obtained for the same tensegrity member. This difference is computed in absolute values and is divided by the maximum allowed stress in each member group ( $\mathrm{N}_{\text {lim,mgroup }}$ ) as shown in Eq. 4. The difference between the maximum stress in the structure before actuation and after actuation is taken into account instead of an averaged value to prevent compensation between stress values after actuation.

$$
\operatorname{MDiff}_{d}(\text { mgroup })=\underset{i \in \text { mgroup }}{\operatorname{Max}}\left(\frac{\left|a N_{i, d}-d N_{i, d}\right|}{N_{\text {lim, } i}}\right)
$$

Once all 65 damage cases are simulated, the stress efficiency (S_eff $f_{c, a}$ ) of cable $(c)$ when it is actuated with the value (a) is calculated as the sum of all stress differences (MDiff $_{\text {) }}$ with a penalization term. Penalization is carried out when the maximum stress in a member group exceeds the allowed stress. The penalization aims to alter the efficiency of cables that may result in member failure when actuated. In Eq. 5, $\mathrm{n}$ is the number of damage cases where the penalization is needed. Since member failure due to actuation is penalized, this strategy increases the reliability of the actuation system in terms of damage tolerance. The penalization is computed based on the maximum value of stress difference for each member group.

$$
S_{-} \text {eff } f_{c, a}(\text { mgroup })=1 / 65\left(\sum_{d=1}^{65} \operatorname{MDiff}_{d}(\text { mgroup })+n \cdot \operatorname{Max}_{d}(\operatorname{MDiff}(\text { mgroup }))\right)
$$

The Stress Index (SI) for cable (c), is calculated by summing-up force efficiencies for various member groups obtained for actuation values running between $-5 \mathrm{~cm}$ and $+5 \mathrm{~cm}$ (Eq. 6). Higher values of SI corresponds to worse actuation effects.

$$
\begin{gathered}
S I_{c}=\sum_{a=-5}^{+5}\left(S_{-} \text {eff } f_{c, a}(\text { Layer cables })+S_{-} \text {eff } f_{c, a}(x-\text { cables })\right)+ \\
S_{-} \text {eff } f_{c, a}(\text { Int. struts })+S_{-} \text {eff } f_{c, a}(\text { Diag. struts })
\end{gathered}
$$

\subsection{Pareto filtering}

The performance of each potential active cable is now evaluated through two indices: deflection (DI) and stress (SI).

Instead of employing a weighted sum of the two conflicting criteria, (DI) and (SI), a Pareto multicriteria approach is applied to select best candidate cables for active control. In a multiobjective task, a solution $\mathrm{x}^{*}$ is called Pareto optimal (or nondominated solution) if no feasible 
vector of decision variables can be found that improves values for any objective function without causing a simultaneous increase in other objectives.

The two decision indices are calculated for all potential active cables in the tensegrity structure. The symmetry of the structure and continuity of some cable members allow the reduction of the number of these potential candidates to 35 cables. Recall that Pareto filtering is carried out for an actuation length interval of $-5 \mathrm{~cm}$ ( $5 \mathrm{~cm}$ of contraction) to $+5 \mathrm{~cm}$ ( $5 \mathrm{~cm}$ of elongation). Figure 4 demonstrates the outcomes of Pareto filtering. With the purpose of a better visualization only, in Figure 4, the stress criterion is reported as the value of the stress index (SI) multiplied by 100 while the deflection criterion is the inverse of the Deflection Index (DI).

Figure 4. Pareto filtering

Pareto filtering shows that the Pareto front is composed of four cables (64, 62, 39 and 42) which can be considered as the most efficient cables. Cables 62 and 64 are layer cables of the middle pentagon of the bridge while cable 39 and 42 are continuous noncoplanar x-cables.

The Pareto filtering results are further studied to evaluate the efficiency of cable groups. We progressively removed Pareto front solutions and identified new set of nondominated solutions. This strategy allows for a first classification of cable groups based on their double-criteria efficiency (Table 2). The 28 cable elements showed in Figure 4 are thus grouped into 7 groups ranked from the best to the worst. At this stage, the classification performed is based on Pareto optimality without using an MCDM methodology.

Table 2. Ranking of the best cable groups using Pareto filtering

\begin{tabular}{lc}
\hline Pareto set & Cable Numbers \\
\hline 1 & $39,42,62,64$ \\
2 & $25,27,66,69$ \\
3 & $24,26,29,30,33$ \\
4 & $34,37,38,41,65,74,83,84$ \\
5 & $61,70,77$ \\
6 & $78,81,73$ \\
7 & 23 \\
\hline
\end{tabular}

\subsection{Outranking employing MCDM strategies}

Pareto filtering permits the establishment of partially sorted groups of cable elements. The efficiency of cable elements to be actively controlled for damage tolerance is further investigated employing two Multi-Criteria Decision Making (MCDM) approaches: a preference- 
Korkmaz,S. Bel Hadl Ali, N. and Smith, I.F.C. "Configuration of control system for damage tolerance of a tensegrity bridge" Advanced Engineering Informatics, 26, 2012, pp 145-155 doi:10.1016/j.aei.2011.10.002

based outranking method called PROMETHEE (Preference Ranking Organization METHod for Enrichment Evaluation [22]) and a tradeoff-analysis technique called PEG-MCDM [31]. The two techniques belong to MCDM strategies that can be employed for the selection of the "best solution" among a Pareto optimum set.

A short description of these two methods is given below.

\subsubsection{PROMETHEE}

PROMETHEE is an outranking strategy that incorporates preference relations to define a partial or complete order of Pareto solutions [19]. In PROMETHEE, a preference index is used to compute a net flow for each Pareto optimal solution. This value is then used to rank the Pareto set.

Let $S_{1}, S_{2}, \ldots S_{i}, \ldots S_{n}$ be $n$ Pareto optimal solutions and $f_{1}, f_{2}, \ldots f_{k}, \ldots f_{\mathrm{m}}$ denote the $m$ decision criteria. The preference flow $\left(\varphi\left(S_{i}\right)\right)$ for each solution is formulated as follows:

$$
\begin{aligned}
& \varphi\left(S_{i}\right)=\varphi^{+}\left(S_{i}\right)-\varphi^{-}\left(S_{i}\right) \\
& \varphi^{+}\left(S_{i}\right)=\sum_{j=1}^{m} C\left(S_{i}, S_{j}\right) \\
& \varphi^{-}\left(S_{i}\right)=\sum_{j=1}^{m} C\left(S_{j}, S_{i}\right)
\end{aligned}
$$

The preference flow $\left(\varphi\left(S_{i}\right)\right)$ is calculated based on pairwise comparisons between the solutions. The positive flow $\left(\varphi^{+}\left(S_{i}\right)\right)$ expresses the intensity of preference of the solution $S_{i}$ over all other solutions in the solution set. The negative flow $\left(\varphi^{-}\left(S_{i}\right)\right)$ expresses the intensity of preference of all other solutions over solution $S_{i}$. The difference between the positive and the negative flow gives the preference flow $\left(\varphi\left(S_{i}\right)\right)$, which is the absolute preference of the solution $S_{i}$ over all other solutions in the solution set. This value is thus used to establish a complete preorder on the set of possible solutions.

The preference index $C\left(S_{i}, S_{i}\right)$ is defined in Eq. 10, where $w_{k}$ are weights expressing the relative importance of the decision criteria.

$$
C\left(S_{i}, S_{j}\right)=\sum_{k=1}^{n} w_{k} \cdot P_{k}\left(S_{i}, S_{j}\right) / \sum_{k=1}^{n} w_{k}
$$

The basic assumption behind PROMETHEE is that the preference between two solutions on a given criterion can be expressed using ratios. Brans and Mareschal [23] proposed six types of preference functions $P_{k}\left(S_{i}, S_{j}\right)$ used to express the magnitude of the preference between two actions $S_{i}$ and $S_{j}$ on the criterion $k$ by a real value in the interval $[0,1]$. Through these functions, indifference or gradual degrees of preference are associated with the deviations observed between the evaluations of two solutions. For example, the preference function $P_{k}$ for a 
Korkmaz,S. Bel Hadl Ali, N. and Smith, I.F.C. "Configuration of control system for damage tolerance of a tensegrity bridge" Advanced Engineering Informatics, 26, 2012, pp 145-155 doi:10.1016/j.aei.2011.10.002

criterion $k$ returns, for a difference $d$ between two evaluations on that criterion, a value $P_{k}(d)$ between 0 and 1.

PROMETHEE is applied using linear preference functions (Eq.11 and 12) and the same weight $\left(w_{1}=w_{2}=1\right)$ is considered for the two decision criteria since deflection and stress indices are equally important in terms of efficiency. The preference functions P1 and P2 correspond to deflection and stress criteria respectively.

$$
\begin{aligned}
& P_{1}\left(S_{i}, S_{j}\right)= \begin{cases}0 & \text { if } F_{1}\left(S_{i}\right) \leq F_{1}\left(S_{j}\right) \\
\left(F_{1}\left(S_{i}\right)-F_{1}\left(S_{j}\right)\right) /\left(F_{1}^{\max }-F_{1}^{\min }\right) & \text { if } F_{1}\left(S_{i}\right)>F_{1}\left(S_{j}\right)\end{cases} \\
& P_{2}\left(S_{i}, S_{j}\right)= \begin{cases}0 & \text { if } F_{2}\left(S_{i}\right) \geq F_{2}\left(S_{j}\right) \\
\left(F_{2}\left(S_{i}\right)-F_{2}\left(S_{j}\right)\right) /\left(F_{2}^{\min }-F_{2}^{\max }\right) & \text { if } F_{2}\left(S_{i}\right)<F_{2}\left(S_{j}\right)\end{cases}
\end{aligned}
$$

The preference flow $\left(\varphi\left(S_{i}\right)\right)$ is calculated for each solution of the Pareto optimum sets identified through Pareto filtering and a complete preorder is established for each Pareto set of cables (Table 3).

\subsubsection{PEG-MCDM}

Grierson [21] proposed PEG-MCDM as a tradeoff-analysis technique to identify a unique compromise solution for which the competing criteria are mutually satisfied in a Pareto optimum set. The proposed strategy is summarized here for the case of two-criterion decision task. Refer to Grierson [21] for detailed description of the general case with multiple-criterion decision problems.

Having the Pareto-optimal set of solutions of a multi-objective optimization task, let $f_{1}, f_{2}, \ldots, f_{n}$ denote the $n$ vectors that define the Pareto-optimal data constituted by $m$ Pareto-optimal solutions. The original Pareto data are first normalized (Eq.13) to find m-dimensional vectors $x_{i}$ $(i=1, \ldots, n)$.

$$
x_{i}=f_{i}-f_{i}^{\min } / f_{i}^{\max }-f_{i}^{\min } ; \quad(i=1, n)
$$

The $m$ entries of each of the $n$ vectors are sequentially reordered from their minimum to maximum. For $n=2$ decision criteria, the Pareto data are thus represented by two $\mathrm{m}$ dimensional normalized vectors (Eq.14).

$$
\mathbf{x}_{1}^{T}=\left[x_{1}^{\min }, \ldots, x_{1}^{\max }\right] \text { and } \mathbf{x}_{2}^{T}=\left[x_{2}^{\max }, \ldots, x_{2}^{\min }\right]
$$

Grierson [21] proposes to transform the Pareto data, without changing its ordinal character in order to obtain a competitive equilibrium state at which a Pareto tradeoff can take place between the two criteria (Figure 5). This is done by transforming the normalized Pareto curve 
Korkmaz,S. Bel Hadl Ali, N. and Smith, I.F.C. "Configuration of control system for damage tolerance of a tensegrity bridge" Advanced Engineering Informatics, 26, 2012, pp 145-155 doi:10.1016/j.aei.2011.10.002

$(P C)$ to a circular Pareto curve $\left(P C_{0}\right)$ having only one competitive equilibrium state. In order to analytically perform this transformation, the criteria vectors $x_{1}$ and $x_{2}$ are uniformly shifted and then re-normalized to obtain vectors $x_{1}{ }^{*}$ and $x_{2}{ }^{*}$ (Eq.15) which define the dashed Pareto curve PC* in Fig. 5.

$$
\mathbf{x}_{i}^{*}=\left(\mathbf{x}_{i}-\delta \mathbf{x}_{i}\right) /\left(1-\delta x_{i}\right) \quad(i=1,2) \quad ; \quad \delta x_{1}=\delta x_{2}=\sqrt{2}-1
$$

In Equation 15, $\delta \mathbf{x}_{1}$ and $\delta \mathbf{x}_{2}$ are m-dimensional vectors of the shift parameters $\delta x_{1}$ and $\delta x_{2}$. The point at which the transformed Pareto curve $P C^{*}$ intersects with the diagonal line $\left(\mathrm{O}_{A} \mathrm{O}_{B}\right)$ is then shifted with a radial distance $\Delta r_{0}$ to meet the intersection point $E_{0}$ (Figure 5). The coordinates of the point at which the transformed Pareto curve PC* intersects with the diagonal line $\left(\mathrm{O}_{A} \mathrm{O}_{B}\right)$ are calculated employing interpolation if necessary. Therefore, the radial shift $\Delta r_{0}$ from the $\mathrm{PC}^{*}$ curve to point $\mathrm{E}_{0}$ on the $\mathrm{PC}_{0}$ curve is evaluated.

The objective criteria values corresponding to the unique competitive equilibrium point $\mathrm{E}_{0}$ are evaluated using Eq. 16.

$$
f_{i}^{0}=f_{i}^{\max }-\left(f_{i}^{\max }-f_{i}^{\min }\right)\left(\Delta r_{0}+\sqrt{2} / 2\right) ; \quad(i=1,2)
$$

where $f_{1}{ }^{0}$ and $f_{2}{ }^{0}$ are the values of the two objective functions for the Pareto-compromise solution.

Figure 5. Transformation procedure of Pareto data to obtain the compromise solution (after [21])

The best compromise solution for each Pareto set is also calculated through PEG-MCDM strategy (Table 3). The compromise solution is only a fictitious solution as it does not correspond to any particular solution in the Pareto front. Consequently, PROMETHEE and PEGMCDM results are compared through calculating the distance $D\left(S_{i}, S^{*}\right)$ between each Pareto solution $\left(S_{i}\right)$ and the compromise solution $\left(S^{*}\right)$. The 2-dimensional Euclidean distance is used (Eq.17).

$$
D\left(S_{i}, S^{*}\right)=\sqrt{\left(D I\left(S_{i}\right)-D I\left(S^{*}\right)\right)^{2}+\left(S I\left(S_{i}\right)-S I\left(S^{*}\right)\right)^{2}}
$$

\subsubsection{Outranking results}

In order to have a closer insight into the efficiency of cable elements for damage-tolerance control task, a preorder is performed among all cable candidates. Outranking is performed using PROMETHEE and PEG-MCDM. Results in Table 3 show that the preferred solution identified through PROMETHEE is close to the best compromise solution identified through PEG-MCDM. In 
Korkmaz,S. Bel Hadl Ali, N. and Smith, I.F.C. "Configuration of control system for damage tolerance of a tensegrity bridge" Advanced Engineering Informatics, 26, 2012, pp 145-155 doi:10.1016/j.aei.2011.10.002

two of the six studied Pareto sets, the best ranked solution is the closest Pareto solution to the compromise solution (Pareto sets 2 and 3). In all other cases, the closest Pareto solution to the compromise solution is well ranked through PROMETHEE. These results show that a compromise solution is not always the preferred solution in PROMETHEE sense. It is conjectured that the differences between the best compromise solution (PEG-MCDM) and the preferred solution (PROMETHEE) arises because of the compensatory nature of PROMETHEE method, which is not the case for the PEG-MCDM strategy. In PROMETHEE a slight decline in one criterion is acceptable if it is compensated by some enhancement in one or more other criterions. However, the best compromise solution obtained through PEG-MCDM represents a mathematically-derived Pareto tradeoff that is equally beneficial for all objective criteria.

Table 3. Outranking results: comparing PROMETHEE to PEG-MCDM

\begin{tabular}{|c|c|c|c|c|c|c|c|c|c|}
\hline \multirow{2}{*}{$\begin{array}{l}\text { Pareto } \\
\text { set }\end{array}$} & \multirow{2}{*}{$\begin{array}{l}\text { Cable } \\
\mathrm{N}^{\circ}\end{array}$} & \multicolumn{2}{|c|}{$\begin{array}{l}\text { Deflection and } \\
\text { Stress Indices }\end{array}$} & \multicolumn{4}{|c|}{ PROMETHEE } & \multicolumn{2}{|c|}{ PEG-MCDM } \\
\hline & & DI & $\mathrm{SI}$ & $\varphi^{+}\left(S_{i}\right)$ & $\varphi^{-}\left(S_{i}\right)$ & $\varphi\left(S_{i}\right)$ & Rank & $\begin{array}{l}\text { Compromise } \\
\text { solution, } S^{*}\end{array}$ & $D\left(S_{i}, S^{*}\right)$ \\
\hline \multirow{4}{*}{1} & 64 & 0.263 & 0.122 & 1.777 & 1.688 & 0.089 & 3 & \multirow{4}{*}{$(0.172,0.079)$} & 0.100 \\
\hline & 62 & 0.254 & 0.099 & 1.893 & 0.935 & 0.959 & 1 & & 0.084 \\
\hline & 39 & 0.132 & 0.086 & 0.845 & 1.982 & -1.140 & 4 & & 0.041 \\
\hline & 42 & 0.083 & 0.035 & 2.312 & 2.222 & 0.089 & 2 & & 0.099 \\
\hline \multirow{4}{*}{2} & 66 & 0.121 & 0.223 & 1.655 & 1.710 & -0.055 & 4 & \multirow{4}{*}{$(0.074,0.126)$} & 0.107 \\
\hline & 69 & 0.118 & 0.217 & 1.602 & 1.643 & -0.041 & 2 & & 0.100 \\
\hline & 25 & 0.058 & 0.102 & 1.698 & 1.547 & 0.151 & 1 & & 0.030 \\
\hline & 27 & 0.020 & 0.045 & 2.290 & 2.345 & -0.055 & 3 & & 0.098 \\
\hline \multirow{5}{*}{3} & 29 & 0.097 & 0.433 & 2.601 & 2.823 & -0.222 & 3 & \multirow{5}{*}{$(0.061,0.234)$} & 0.203 \\
\hline & 26 & 0.093 & 0.426 & 2.443 & 2.779 & -0.336 & 5 & & 0.194 \\
\hline & 24 & 0.049 & 0.155 & 2.446 & 1.471 & 0.975 & 1 & & 0.080 \\
\hline & 33 & 0.014 & 0.089 & 2.168 & 2.363 & -0.195 & 2 & & 0.152 \\
\hline & 30 & 0.013 & 0.087 & 2.177 & 2.399 & -0.222 & 4 & & 0.154 \\
\hline \multirow{8}{*}{4} & 38 & 0.044 & 0.406 & 2.996 & 3.782 & -0.786 & 8 & \multirow{8}{*}{$(0.030,0.213)$} & 0.193 \\
\hline & 41 & 0.043 & 0.394 & 2.801 & 3.563 & -0.762 & 6 & & 0.181 \\
\hline & 34 & 0.035 & 0.259 & 2.196 & 1.574 & 0.622 & 1 & & 0.046 \\
\hline & 37 & 0.035 & 0.256 & 2.172 & 1.562 & 0.609 & 2 & & 0.043 \\
\hline & 83 & 0.029 & 0.213 & 2.073 & 1.661 & 0.412 & 3 & & 0.001 \\
\hline & 84 & 0.029 & 0.210 & 2.081 & 1.697 & 0.384 & 4 & & 0.003 \\
\hline & 74 & 0.026 & 0.188 & 2.331 & 2.025 & 0.307 & 5 & & 0.026 \\
\hline & 65 & 0.010 & 0.077 & 4.218 & 5.004 & -0.786 & 7 & & 0.138 \\
\hline \multirow{3}{*}{5} & 77 & 0.025 & 0.193 & 1.950 & 1.9401 & 0.010 & 1 & \multirow{3}{*}{$(0.017,0.141)$} & 0.053 \\
\hline & 70 & 0.010 & 0.094 & 0.990 & 1.0096 & -0.019 & 3 & & 0.047 \\
\hline & 61 & 0.009 & 0.088 & 1.060 & 1.0503 & 0.010 & 2 & & 0.053 \\
\hline
\end{tabular}


Korkmaz,S. Bel Hadl Ali, N. and Smith, I.F.C. "Configuration of control system for damage tolerance of a tensegrity bridge" Advanced Engineering Informatics, 26, 2012, pp 145-155 doi:10.1016/j.aei.2011.10.002

\begin{tabular}{llllllllll} 
& 81 & 0.016 & 0.315 & 1.189 & 1.0285 & 0.160 & $\mathbf{2}$ & 0.102 \\
6 & 78 & 0.014 & 0.309 & 0.840 & 1.1601 & -0.320 & $\mathbf{3}$ & $(0.012,0.213)$ & 0.096 \\
& 73 & 0.009 & 0.095 & 1.971 & 1.8114 & 0.160 & $\mathbf{1}$ & & 0.118 \\
\hline
\end{tabular}

In order to classify the 28 candidate active members, the preference flow $\left(\varphi\left(S_{i}\right)\right)$ is calculated again for each solution of the 28-member set so that a complete preorder is established (Table 4). Outranking results slightly differ from those obtained in Table 3 since for this complete preorder, both dominated and nondominated solutions are taken into account.

Table 4. Complete preorder of cable members using PROMETHEE

\begin{tabular}{ccccl}
\hline Cable & $\phi^{+}\left(S_{i}\right)$ & $\phi^{-}\left(S_{i}\right)$ & $\phi\left(S_{i}\right)$ & Rank \\
\hline 62 & 28.45 & 0.52 & 27.93 & 1 \\
64 & 28.41 & 1.12 & 27.29 & 2 \\
39 & 16.73 & 1.24 & 15.49 & 3 \\
42 & 15.58 & 1.94 & 13.64 & 4 \\
25 & 9.41 & 3.32 & 6.09 & 5 \\
27 & 10.62 & 4.65 & 5.97 & 6 \\
69 & 10.30 & 5.66 & 4.64 & 7 \\
66 & 10.44 & 5.88 & 4.56 & 8 \\
65 & 8.26 & 5.58 & 2.69 & 9 \\
30 & 7.66 & 5.40 & 2.26 & 10 \\
33 & 7.58 & 5.35 & 2.23 & 11 \\
61 & 7.54 & 5.81 & 1.73 & 12 \\
24 & 6.68 & 5.17 & 1.51 & 13 \\
70 & 7.22 & 5.84 & 1.38 & 14 \\
73 & 7.18 & 5.91 & 1.27 & 15 \\
23 & 5.12 & 7.34 & -2.22 & 16 \\
74 & 4.10 & 7.46 & -3.36 & 17 \\
77 & 3.88 & 7.73 & -3.85 & 18 \\
84 & 3.54 & 8.17 & -4.63 & 19 \\
83 & 3.48 & 8.28 & -4.80 & 20 \\
37 & 2.87 & 10.12 & -7.26 & 21 \\
34 & 2.84 & 10.25 & -7.41 & 22 \\
26 & 5.41 & 18.16 & -12.76 & 23 \\
29 & 5.71 & 18.60 & -12.88 & 24 \\
78 & 1.18 & 14.39 & -13.21 & 25 \\
81 & 1.14 & 14.66 & -13.52 & 26 \\
41 & 1.72 & 17.75 & -16.03 & 27 \\
38 & 1.70 & 18.44 & -16.74 & 28 \\
\hline & & & &
\end{tabular}

The efficiencies of various member groups composing the tensegrity bridge are further investigated employing the preference flow results given in Table 4. Figure 6 shows the 
Korkmaz,S. Bel Hadl Ali, N. and Smith, I.F.C. "Configuration of control system for damage tolerance of a tensegrity bridge" Advanced Engineering Informatics, 26, 2012, pp 145-155 doi:10.1016/j.aei.2011.10.002

efficiencies of the cables in various groups in terms of active control. Preference flow results are presented only for the cables that are in the first half of the bridge. Cables in the other half of the bridge show the same behavior because of the symmetry along middle pentagon (Figure 1).

Figure 6. a. Preference flow values of the intermediate and middle pentagon layer cables

b. Preference flow values of $x$-cables of the first module (continuous cables are indicated with four point stars)

c. Preference flow values of $x$-cables of the second module

Results shown in Figure 6a indicate that the middle pentagon layer cables are more efficient than the layer cables in intermediate pentagons. This is an expected behavior as the middle pentagon layer cables are closer to the midspan nodes, where the maximum deflection occurs. Cable 62 and 64 are particularly efficient in terms of active control. In fact, these two cables are directly connected to midspan nodes.

Coplanar and noncoplanar $x$-cables are compared in terms of actuation efficiency (Figure 6b). Comparison results suggest that the noncoplanar $\mathrm{x}$-cables are more efficient than coplanar $\mathrm{x}$ cables in general.

Figure $6 c$ involves only the efficiency data of coplanar $x$-cables since the noncoplanar $x$-cables of the second pentagon are given in Figure $6 b$ due to continuous nature of the noncoplanar $x$ cables. Results indicate that coplanar $x$-cables have lower preference flow values than noncoplanar $x$-cables.

The efficiency index values, the average preference flow and the average ranking of cables in the tensegrity bridge are summarized in Table 5. Coplanar $x$-cables have the lowest efficiencies in terms of active control in general. However, the efficiency of some coplanar $x$-cables is particularly high compared to other cables. For example, cable 69, which is a coplanar x-cable located in the second module, has a better efficiency than most layer cables. Having the advantage of being continuous over two modules, noncoplanar $x$-cables have the highest average efficiency value. The two layer cables on the top of the efficiency ranking, Cables 62 and 64 , substantially increase the average efficiency value of layer cables.

Table 5. Efficiency index values of different types of cables

\begin{tabular}{lcccc}
\hline Cable Type & $\begin{array}{c}\text { Deflection } \\
\text { Index }\end{array}$ & Stress Index & $\begin{array}{c}\text { Average } \\
\text { Preference Flow }\end{array}$ & $\begin{array}{c}\text { Average Rank with Respect } \\
\text { to Preference Flow }\end{array}$ \\
\hline Noncoplanar X-Cable & 0.09 & 0.11 & 11.70 & 4 \\
Layer Cable & 0.08 & 0.06 & 9.29 & 8 \\
Coplanar X-Cable & 0.04 & 0.25 & -5.56 & 19 \\
\hline
\end{tabular}


Korkmaz,S. Bel Hadl Ali, N. and Smith, I.F.C. "Configuration of control system for damage tolerance of a tensegrity bridge" Advanced Engineering Informatics, 26, 2012, pp 145-155 doi:10.1016/j.aei.2011.10.002

\section{Damage tolerance through active control}

This section investigates active control ability of cable members to restore the footbridge serviceability conditions thus allowing for a damage tolerant structure. Cable damage is simulated by taking cable members out of the structural analysis model. Only cases where a cable is damaged are considered. Damage to struts or steel frames at the extremities of the structure is not in the scope of this study. Furthermore, the serviceability conditions, which are taken into account in damage tolerance, do not include vibration induced criteria.

Numerical simulations show that the tensegrity bridge is damage tolerant with respect to safety requirements. However, serviceability requirements are not satisfied in some cable damage situations (Table 6). The bridge is thus not capable of accomplishing its function for some damage scenarios. Several case studies are tested numerically to verify the outcomes of the conducted efficiency study. For a given damage scenario, the structural response is controlled through groups of active cables.

Table 6. Greatest midspan deflections for cases of cable damage in the structure

\begin{tabular}{lcccc}
\hline $\begin{array}{c}\text { Damaged } \\
\text { Cable No. }\end{array}$ & Type of Damaged Cable & $\begin{array}{c}\text { Maximum } \\
\text { Deflection } \\
{[\mathrm{cm}]}\end{array}$ & $\begin{array}{c}\text { Maximum } \\
\text { Stress After } \\
\text { Damage [MPa] }\end{array}$ & $\begin{array}{c}\text { Maximum Change in Stresses Due } \\
\text { to Damage [MPa] }\end{array}$ \\
\hline $39,40,75,76$ & Noncoplanar X-Cable & 9.3 & 1060 & 771 \\
$42,45,79,80$ & Noncoplanar X-Cable & 7.2 & 965 & 563 \\
64 & Layer Cable & 5.0 & 731 & 569 \\
62 & Layer Cable & 4.7 & 728 & 542 \\
65 & Layer Cable & 4.4 & 850 & 572 \\
\hline
\end{tabular}

Table 6 gives the damage cases where the maximum deflection in the structure reaches highest values. The dead load of the bridge is assumed to be uniformly distributed in order to provide an accurate comparison of the deflections that occur in nodal locations. The highest values for midspan deflection are obtained when noncoplanar $x$-cables are damaged. Recall that the noncoplanar $\mathrm{x}$-cables are continuous cables that are assumed to run over frictionless pulleys connected to the nodes and the stress limit of cables is $1069 \mathrm{MPa}$. Each continuous cable comprises 4 cable segments. The maximum stress occurs in cables in all cases.

An objective of self-repair is to reduce excessive midspan deflections resulting from cable damage to acceptable levels with a minimum control effort [24]. The internal clearance is not affected by active control. Control effort is defined by the minimum actuation length that is needed to decrease the excessive deflections to the limitation prescribed in the Swiss Code. Active cables of the structure can be elongated or contracted modifying stress distribution and node deflections of the structure. Furthermore, each length adjustment of an active cable is inevitably accompanied with a perturbation in the stress distribution in the tensegrity bridge. 
Korkmaz,S. Bel Hadl Ali, N. and Smith, I.F.C. "Configuration of control system for damage tolerance of a tensegrity bridge" Advanced Engineering Informatics, 26, 2012, pp 145-155 doi:10.1016/j.aei.2011.10.002

A robust approach for self-repair should take into account both deflections and stress criteria. The control task is thus a multi-objective optimization problem with two objective functions. The first objective function is defined as the sum of active-cable length adjustments while the second objective function is defined as the sum of the deviations in stresses caused by an actuation solution (Eq. 18 and 19). The total perturbation of stress due to active control is minimized rather than the maximum stress change at each member in order to take into account and minimize the overall stress change. The overall amount of change in stresses is taken into account while the the maximum stress changes in individual members is monitored to prevent possible local member failure due to control.

Let $\mathrm{I}^{\mathbf{t}}=\left[I_{1}, I_{2}, \ldots, I_{N A}\right]$ be the vector of actuation lengths and $\Delta \mathbf{N}^{\mathrm{t}}=\left[\Delta N_{1}, \Delta N_{2}, \ldots, \Delta N_{N E}\right]$ be the vector of total difference in stresses for all structural members. The damage-tolerance control task can be stated as follows:

$$
\begin{aligned}
& \min f_{1}=\sum_{i=1}^{N A}\left|l_{i}\right| \\
& \min f_{2}=\sum_{j=1}^{N E}\left|\Delta N_{j}\right|
\end{aligned}
$$

subject to

$$
\begin{aligned}
& N_{\text {sd }, j}-N_{R d, j} \leq 0 \quad j=1, \ldots, N E \\
& \delta_{\text {midspan }}-\delta_{\lim } \leq 0 \\
& \delta_{\text {midspan }}^{\prime}-\delta_{\lim } \leq 0 \\
& g_{l, \text { max }}=l_{i, \text { max }}-l_{i} \geq 0, \quad \forall i=1, \ldots, N A \\
& g_{l, \text { min }}=l_{i}-l_{i, \text { min }} \geq 0, \quad \forall i=1, \ldots, N A
\end{aligned}
$$

In these equations $N A$ and $N E$ are the number of active members and the number of structural elements respectively. Eq. 20 defines the local capacity and buckling checks for tensioned and compressed members. $N_{s d, i}$ is the ultimate axial force of member $i$, while $N_{R d, i}$ is axial force resistance of member $i$. Eq. 21 defines the serviceability limit-state requirement of midspan

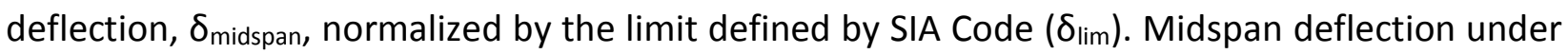
self-weight of the bridge, $\delta^{\prime}$ midspan, is also limited to $\delta_{\lim }($ Eq. 22$)$. This constraint ensures that the active control command determined under SLS load combination will not cause excessive upward deflections when the bridge is not carrying live loads. Eq. 23 and Eq. 24 represent the constraints on the control variable values. We assume that each active cable adjustment $l_{i}$ is limited to values ranging between $\mathrm{I}_{\mathrm{i}, \min }$ and $\mathrm{I}_{\mathrm{i}, \max }$.

Optimization of active control is carried out with the objectives of minimizing the total adjustment length and minimizing the difference in stresses of structural members before and after actuation. Most critical cases are first investigated using 10 active cables that are most 
Korkmaz,S. Bel Hadl Ali, N. and Smith, I.F.C. "Configuration of control system for damage tolerance of a tensegrity bridge" Advanced Engineering Informatics, 26, 2012, pp 145-155 doi:10.1016/j.aei.2011.10.002

efficient in terms of active control (Figure 7a). Subsequently, the same cases are studied in terms of damage tolerance using only the cables that are required to be active for deployment purposes (Figure 7b). Data given in Table 6 suggest that damage in most efficient cables in terms of actuation influences deflections more than damage in other cables. Since these cables are directly connected to the midspan nodes, where maximum deflections occur, actuation or damage of these cables influence the maximum deflection in the structure more than actuation or damage of other cables.

Figure 7. Active cables employed for damage tolerance

A multi-objective genetic algorithm is employed to solve the self-repair optimization task. Optimization variables are coded as real strings. Penalty functions are employed to handle control constraints by penalizing individuals that violate constraints. In this manner, the search for Pareto optimum solutions is directed toward feasible regions of the search space. Optimization results are satisfactory for a population size of 40 individuals running for 80 generations. Crossover and mutation probabilities are fixed as 0.9 and 0.1 , respectively. When convergence is achieved, the multi-objective genetic algorithm generates a set of Pareto optimal solutions. The control solution is then selected between mutually nondominated candidates. An outranking relation is employed to select a compromise control solution. As for cable element efficiency, outranking is performed using PROMETHEE. The two objectives of the control task are assigned the same weight and linear preference functions are used to evaluate the Pareto solution set.

Five critical damage cases are investigated to show effectiveness of the proposed methodology. Two groups of active cables are compared in terms of actuation efficiency. The first group involves 10 cables that have highest actuation efficiency. On the other hand, the second group comprises 10 cables that are required to be active for deployment purposes (Figure 7). The second group members are continuous noncoplanar x-cables.

Figure 8. Pareto optimal solutions obtained with most efficient cables (Cable 42 damaged)

Figure 9. Pareto optimal solutions obtained with deployment cables (Cable 42 damaged)

Figures 8 and 9 present sample calculations for control solutions. Control solutions obtained with the 10 most efficient cables are presented in Figure 8. Figure 9 gives the control solutions obtained when the 10 cables required for deployment are used for damage tolerance control. The Pareto optimum set is displayed with respect to two objectives of the control task. The arrows in the two foregoing figures point the control solution obtained employing PROMETHEE outranking. 
Korkmaz,S. Bel Hadl Ali, N. and Smith, I.F.C. "Configuration of control system for damage tolerance of a tensegrity bridge" Advanced Engineering Informatics, 26, 2012, pp 145-155 doi:10.1016/j.aei.2011.10.002

Results for five damage cases are summarized in Table 7. Maximum deflection in the bridge after damage before actuation is given in the third column. Maximum actuation length in one active cable and the total actuation length of all active cables are given in the fourth and the fifth columns, respectively. The sixth column gives the total difference in stresses of all members in the structure. The maximum difference of stresses in one member is given in the last column. Optimization and outranking results indicate that damage tolerance can be provided utilizing active cables. Excessive deflections caused by damage are diminished using 10 cables at each damage case. The deflection limit for this structure $(2.66 \mathrm{~cm})$ is verified for every case. This comparison shows that it is possible to achieve damage tolerance objectives using the actuation scheme intended for the deployment task. Furthermore, in many damage cases, the control cost required to achieve damage tolerance using the deployment configuration for active members is close to the optimal control cost of the actuation solution identified using the most efficient configuration of active members. Therefore, deployment functionality does not significantly compromise damage tolerance requirements.

Table 7. Damage tolerance with different groups of cables

\begin{tabular}{|c|c|c|c|c|c|c|}
\hline $\begin{array}{l}\text { Damaged } \\
\text { Cables }\end{array}$ & Active Cables & $\begin{array}{l}\text { Maximum } \\
\text { Deflection } \\
\text { Before } \\
\text { Actuation } \\
(\mathrm{cm})\end{array}$ & $\begin{array}{l}\text { Maximum } \\
\text { Actuation } \\
\text { Length } \\
(\mathrm{mm})\end{array}$ & $\begin{array}{l}\text { Total } \\
\text { Actuation } \\
\text { Length } \\
(\mathrm{mm})\end{array}$ & $\begin{array}{c}\text { Total } \\
\text { Difference } \\
\text { in Stress } \\
\text { (MPa) }\end{array}$ & $\begin{array}{c}\text { Maximum } \\
\text { Difference } \\
\text { in Stresses } \\
(\mathrm{MPa})\end{array}$ \\
\hline $39,40,75,76$ & Most Efficient Cables & 9.3 & 60 & 420.1 & 10644 & 360 \\
\hline \multicolumn{2}{|c|}{$39,40,75,76$ Cables Required for Deployment } & 9.3 & 65 & 455.6 & 5670 & 202 \\
\hline $42,45,79,80$ & Most Efficient Cables & 7.2 & 50 & 157.9 & 5300 & 286 \\
\hline \multicolumn{2}{|c|}{$42,45,79,80$ Cables Required for Deployment } & 7.2 & 50 & 197.5 & 3029 & 105 \\
\hline 64 & Most Efficient Cables & 5.0 & 30 & 95.7 & 3361 & 135 \\
\hline 64 & Cables Required for Deployment & 5.0 & 30 & 102.8 & 2036 & 53 \\
\hline 62 & Most Efficient Cables & 4.7 & 30 & 84.6 & 2737 & 107 \\
\hline 62 & Cables Required for Deployment & 4.7 & 30 & 97.4 & 1637 & 48 \\
\hline 65 & Most Efficient Cables & 4.4 & 25 & 57.7 & 1850 & 76 \\
\hline 65 & Cables Required for Deployment & 4.4 & 25 & 91.6 & 1217 & 38 \\
\hline
\end{tabular}

Results show that the required total actuation lengths are longer for cases where maximum deflections before actuation are greater. Results also suggest that the cable group comprising the most efficient cables in terms of actuation can provide damage tolerance with shorter actuation lengths than that of the cable group involving the cables that are required for deployment function. However, the total difference in stresses is greater at each case when damage tolerance is provided by the active cable group of most efficient cables. Since all cables required for deployment are continuous and four times longer than discontinuous cables, the difference in stresses that occur in these cables are much smaller than differences in stresses that come about in active cables when discontinuous cables are actuated. In view of the fact 
Korkmaz,S. Bel Hadl Ali, N. and Smith, I.F.C. "Configuration of control system for damage tolerance of a tensegrity bridge" Advanced Engineering Informatics, 26, 2012, pp 145-155 doi:10.1016/j.aei.2011.10.002

that the active cables are among the most loaded members in the structure, the results are in conformity with expectations.

\section{Conclusions}

This paper focuses on active control configuration for damage tolerance of a tensegrity bridge. Deflection and stress indices are proposed to evaluate the relative efficiencies of active member candidates in meeting the objectives of damage tolerance task. Pareto filtering, PEG-MCDM and preference-based outranking through PROMETHEE are used to identify the best configuration of active members. The damage tolerance control task is formulated as a multi-objective optimization problem. Control commands are identified using stochastic search through genetic algorithms and PROMETHEE outranking strategy. Moreover, the proposed methodology is applicable to a range of complex active structures. The conclusions drawn from this study are as follows:

- The control strategy adopted in this study is capable of meeting damage tolerance objectives.

- PROMETHEE has the potential to identify optimally directed solutions for efficient active control systems. Furthermore, Pareto filtering and preference-based outranking through PROMETHEE can be used as complementary techniques for feature selection taking into account conflicting criteria.

- A comparison between PROMETHEE and the PEG-MCDM strategy shows that the best compromise solution identified through PEG-MCDM is very close to the solution that is best ranked through PROMETHEE. It is conjectured that the difference between the best compromise solution (PEG-MCDM) and the preferred solution (PROMETHEE) arises from the compensatory nature of PROMETHEE method, which is not present in the PEGMCDM strategy.

- This study shows that it is possible to meet damage tolerance objectives using the actuation scheme intended for the deployment task. In many damage cases, control cost (in terms of total actuation length and total difference in stresses) using the deployment configuration for active members is very close to the optimal control cost of the control solution identified using the best configuration of active members. Therefore, deployment functionality does not significantly compromise damage tolerance requirements. 
Korkmaz,S. Bel Hadl Ali, N. and Smith, I.F.C. "Configuration of control system for damage tolerance of a tensegrity bridge" Advanced Engineering Informatics, 26, 2012, pp 145-155 doi:10.1016/j.aei.2011.10.002

\section{Acknowledgements}

The authors would like to thank Prof René Motro (University of Montpellier), the originator of the hollow-bridge concept, and $\mathrm{Dr}$ Simon Guest (University of Cambridge) for helpful discussions. This research was partially funded by the Swiss National Science Foundation under Grant No 20020-121552.

\section{References}

[1] K. Shea, E. Fest, I.F.C. Smith, Developing intelligent tensegrity structures with stochastic search, Advanced Engineering Informatics, 16 (2002) 21-40.

[2] G.W. Housner, L.A. Bergman, B. Caughey, Structural Control: Past, Present, and Future, Journal of Engineering Mechanics 123 (1997) 897-971.

[3] J.T.P. Yao, Concept of structural control, ASCE Journal of the Structural Control, 98 (1972) 1567-1574.

[4] K. Shea, I.F.C. Smith, Intelligent structures: A new direction in structural control, in: Artificial Intelligence in Structural Engineering, Springer LNAI: 1454 398-410, Ascona, Switzerland, 1998.

[5] M. Masic, R.E. Skelton, Selection of prestress for optimal dynamic/control performance of tensegrity structures, International Journal of Solids and Structures, 43 (2006) 2110-2125.

[6] R.E. Skelton, M.C. de Oliveira, Tensegrity Systems, Springer, New York, 2009.

[7] S. Djouadi, R. Motro, J.C. Pons, B. Crosnier, Active Control of Tensegrity Systems, Journal of Aerospace Engineering, 11 (1998) 37-44.

[8] C. Sultan, Modeling, design, and control of tensegrity structures with applications, in: School of Aeronautics and Astronautics, Purdue University, West Lafayette, IN, USA, 1999.

[9] N. Kanchanasaratool, D. Williamson, Modelling and control of class NSP tensegrity structures, International Journal of Control, 75 (2002) 123-139.

[10] J.J.M. Van De Wijdeven, A.G. De Jager, Shape change of tensegrity structures: design and control, in: American Control Conference, Portland, 2005.

[11] E. Fest, K. Shea, B. Domer, I.F.C. Smith, Adjustable Tensegrity Structures, Journal of Structural Engineering, 129 (2003) 515-526.

[12] B. Domer, Performance enhancement of active structures during service lives, in: IMAC, Ecole polytechnique fédérale de lausanne, 2003.

[13] E. Fest, K. Shea, I.F.C. Smith, Active Tensegrity Structure, Journal of Structural Engineering, 130 (2004) 1454-1465.

[14] B. Adam, I. Smith, Tensegrity Active Control: Multi-objective Approach, Journal of Computing in Civil Engineering, 21 (2007) 33-10.

[15] B. Adam, I.F.C. Smith, Active tensegrity: A control framework for an adaptive civil-engineering structure, Computers \& Structures, 86 (2008) 2215-2223.

[16] N. Bel Hadj Ali, I.F.C. Smith, Dynamic behavior and vibration control of a tensegrity structure, Journal of Solids and Structures, 47 (2010) 1285-1296.

[17] N. Ben Kahla, B. Moussa, Effect of a Cable Rupture on Tensegrity Systems, International Journal of Space Structures, 17 (2002) 51-65.

[18] K. Abedi, B. Shekastehband, Effect of member loss on the structural integrity of tensegrity systems, in: IASS Symposium 2009, Evolution and trends in Design, Analysis and Construction of Shell and Spatial Structures, Valencia (Spain), 2009, pp. 2274-2285. 
Korkmaz,S. Bel Hadl Ali, N. and Smith, I.F.C. "Configuration of control system for damage tolerance of a tensegrity bridge" Advanced Engineering Informatics, 26, 2012, pp 145-155 doi:10.1016/j.aei.2011.10.002

[19] C. Coello, G. Lamont, D.V. Veldhuizen, Evolutionary Algorithms for Solving Multi-Objective Problems, 2nd Edition ed., Springer US, 2007.

[20] C. Coello, Handling preferences in evolutionary multiobjective optimization: a survey in: Evolutionary Computation, 2000, pp. 30-37.

[21] D.E. Grierson, Pareto multi-criteria decision making, Advanced Engineering Informatics, 22 (2008) 371-384.

[22] J.P. Brans, P. Vincke, B. Mareschal, How to select and how to rank projects: The PROMETHEE method, European Journal of Operational Research, 24 (1986) 228-238.

[23] J.P. Brans, B. Mareschal, Promethee Methods, Multiple Criteria Decision Analysis: State of the Art Surveys, (2005) 163-186.

[24] S. Korkmaz, N. Bel Hadj Ali, I.F.C. Smith, Determining control strategies for damage tolerance of an active tensegrity structure, Engineering Structures, 33 (2011) 1930-1939.

[25] L. Rhode-Barbarigos, N. Bel Hadj Ali, R. Motro, I.F.C. Smith, Designing tensegrity modules for pedestrian bridges, Engineering Structures, 32 (2010) 1158-1167.

[26] SIA, SIA 260 in, Swiss Society of Engineers and Architects, 2003.

[27] R. Motro, B. Maurin, C. Silvestri, Tensegrity Rings and the Hollow Rope, in: IASS Symposium, New Olympics, New Shells and Spatial Structures, Beijing, 2006, pp. Extended abstract pp 470-471 and complete text in CD.

[28] N. Bel Hadj Ali, L. Rhode-Barbarigos, A.A. Pascual Albi, I.F.C. Smith, Design optimization and dynamic analysis of a tensegrity-based footbridge, Engineering Structures, 32 (2010) 3650-3659.

[29] SIA, SIA 261, in, Swiss Society of Engineers and Architects, 2003.

[30] N. Bel Hadj Ali, L. Rhode-Barbarigos, I.F.C. Smith, Analysis of clustered tensegrity structures using a modified dynamic relaxation algorithm, International Journal of Solids and Structures, 48 (2011) 637-647. [31] D.E. Grierson, Pareto multi-criteria decision making, Adv. Eng. Inform., 22 (2008) 371-384. 


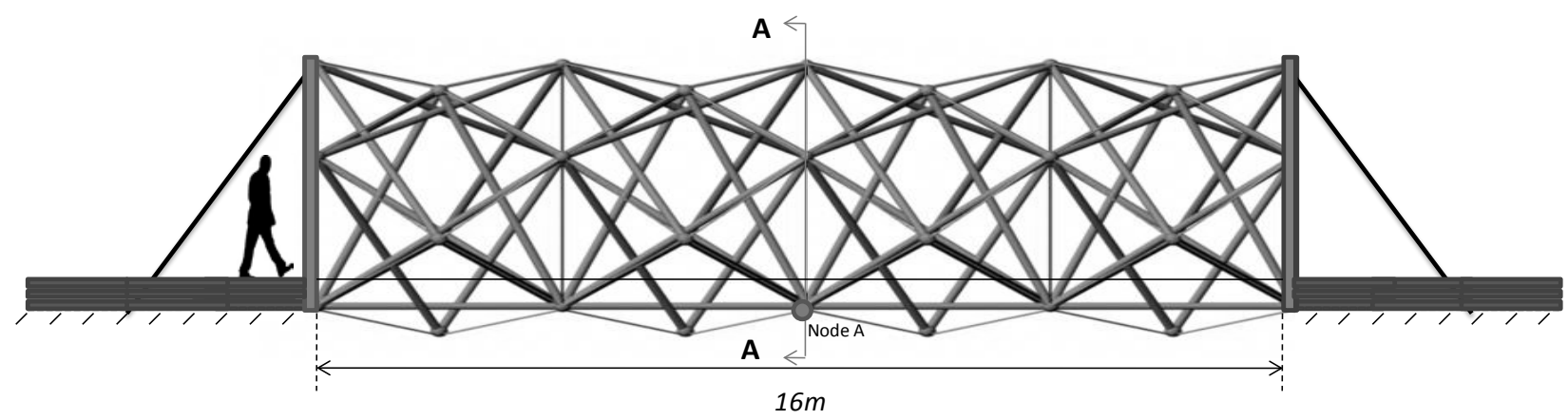

Figure 1. Tensegrity bridge (thick lines denote bars while thin lines denote cables)
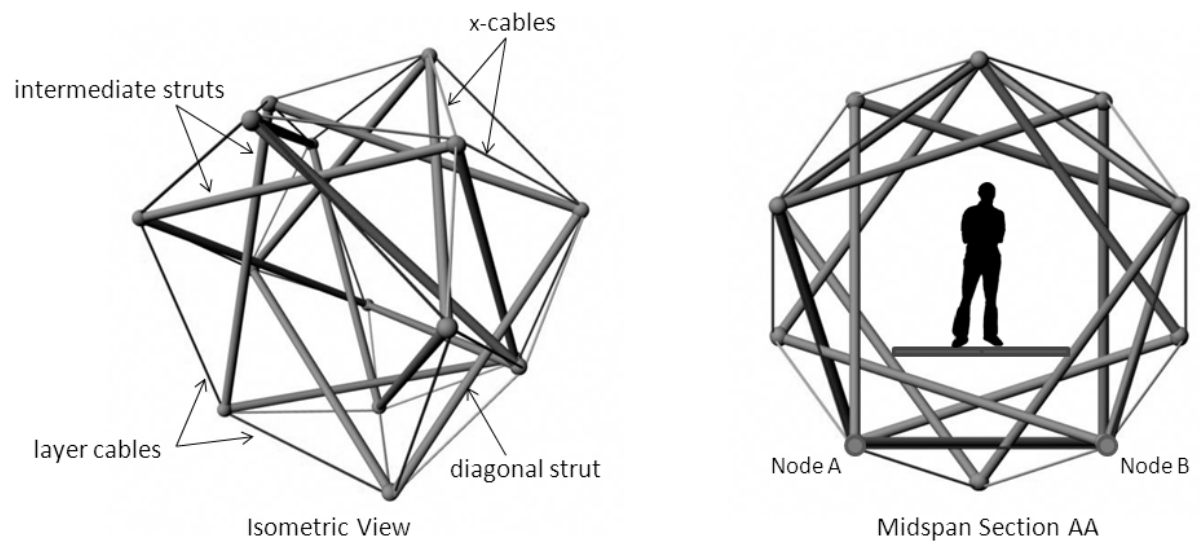

Figure 2. Pentagon module (thick lines denote bars while thin lines denote cables) 


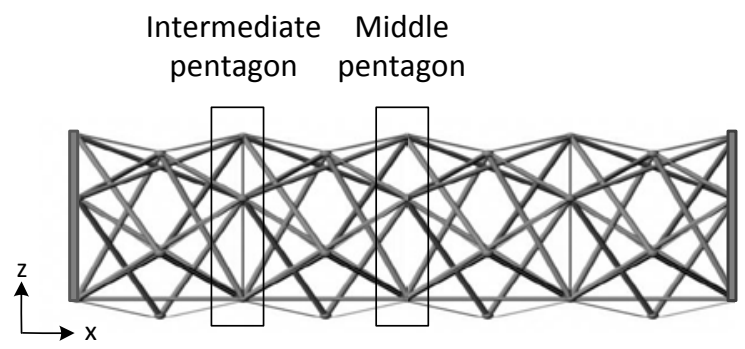

Module 1 Module 2 Module 3 Module 4

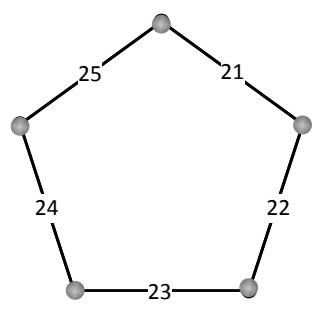

Intermediate pentagon

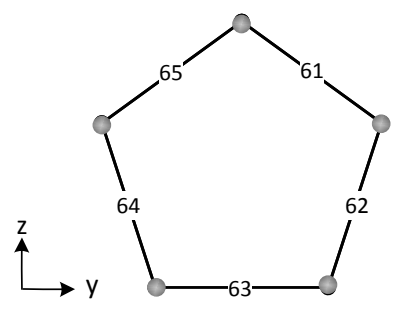

Middle pentagon

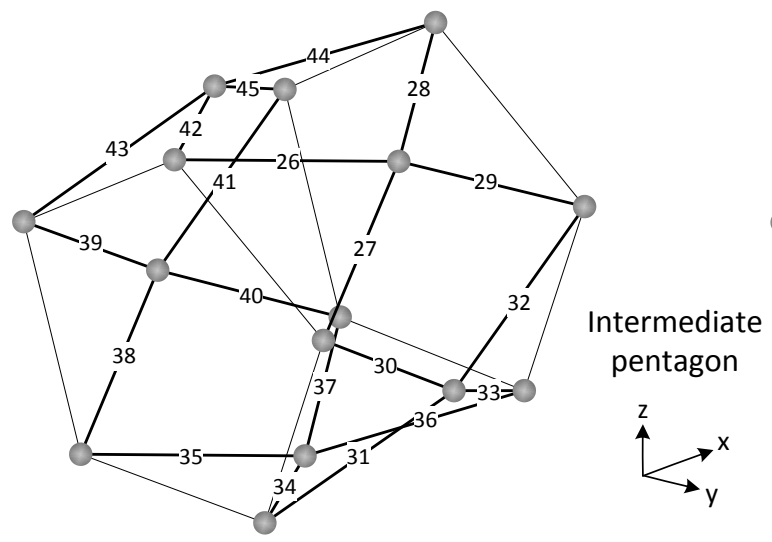

Module 1

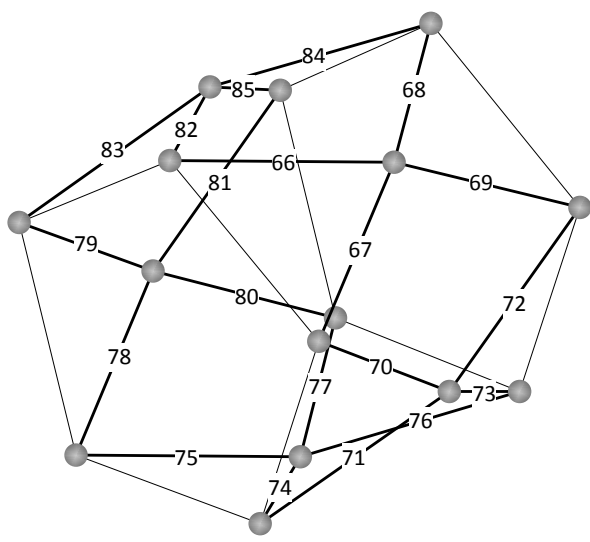

Module 2

Figure 3. Views of the tensegrity bridge with cable numbers for the two first modules 
Korkmaz,S. Bel Hadl Ali, N. and Smith, I.F.C. "Configuration of control system for damage tolerance of a tensegrity bridge" Advanced Engineering Informatics, 26, 2012, pp 145-155 doi:10.1016/j.aei.2011.10.002

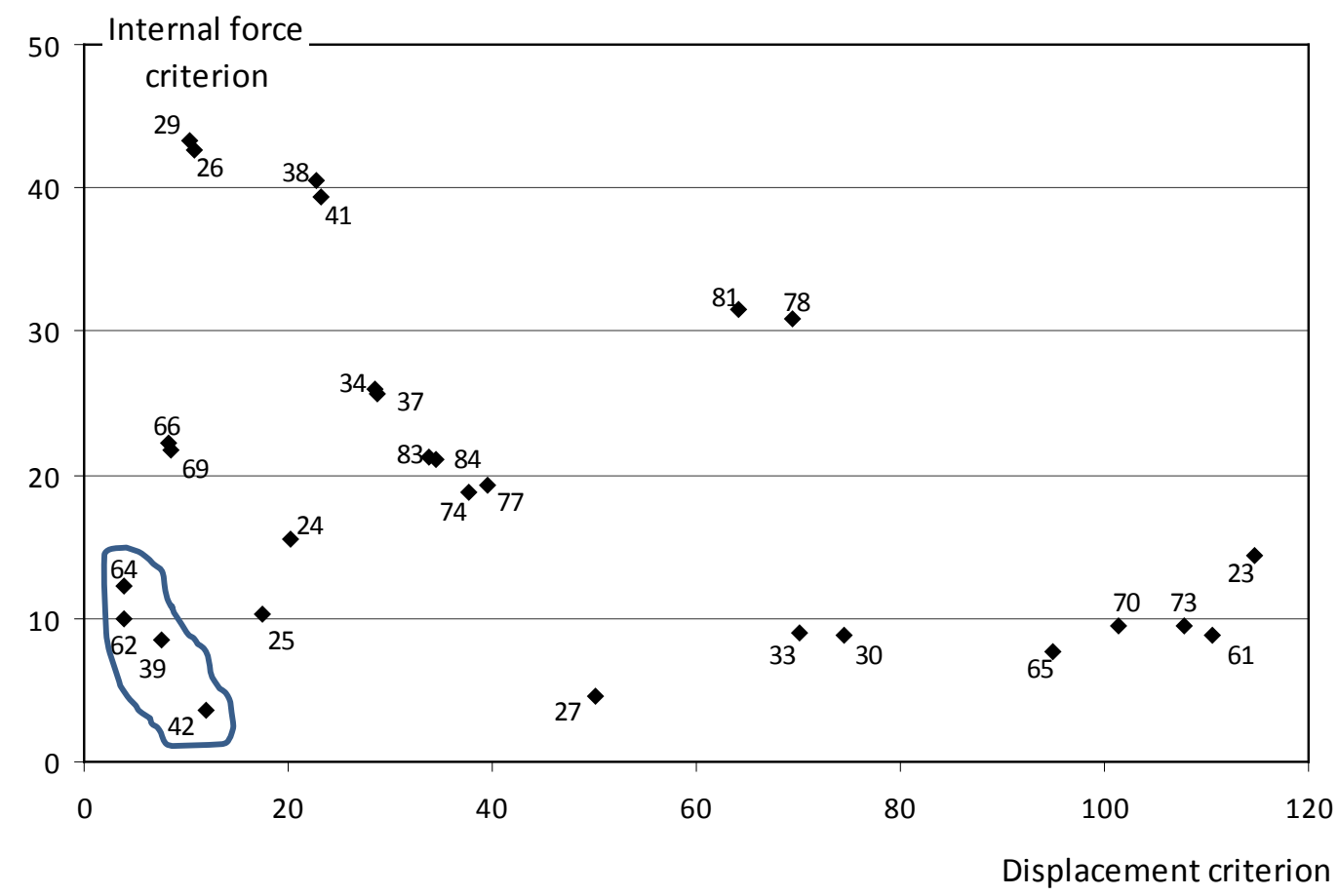

Figure 4. Pareto filtering 
Korkmaz,S. Bel Hadl Ali, N. and Smith, I.F.C. "Configuration of control system for damage tolerance of a tensegrity bridge" Advanced Engineering Informatics, 26, 2012, pp 145-155 doi:10.1016/j.aei.2011.10.002

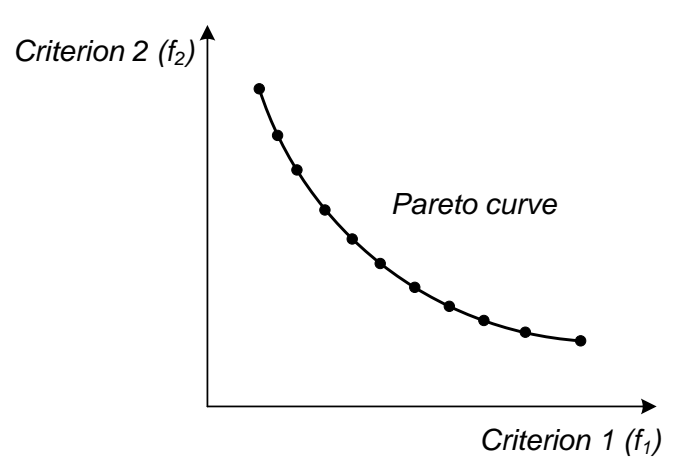

(a) Input Pareto data

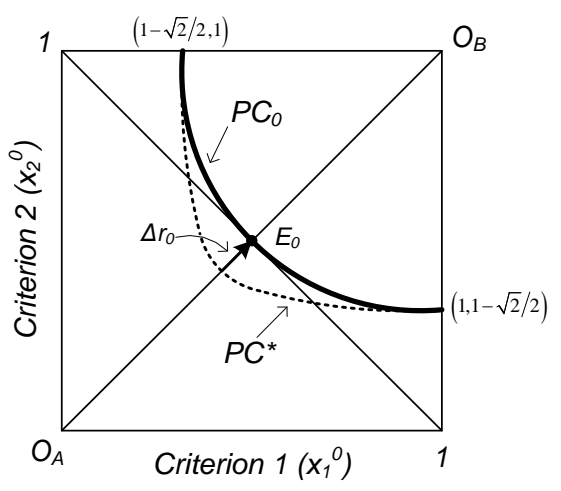

(b) Shifted and circular Pareto curves

Figure 5. Transformation procedure of Pareto data to obtain the compromise solution (after [21]) 
Korkmaz,S. Bel Hadl Ali, N. and Smith, I.F.C. "Configuration of control system for damage tolerance of a tensegrity bridge" Advanced Engineering Informatics, 26, 2012, pp 145-155 doi:10.1016/j.aei.2011.10.002

Preference Flow

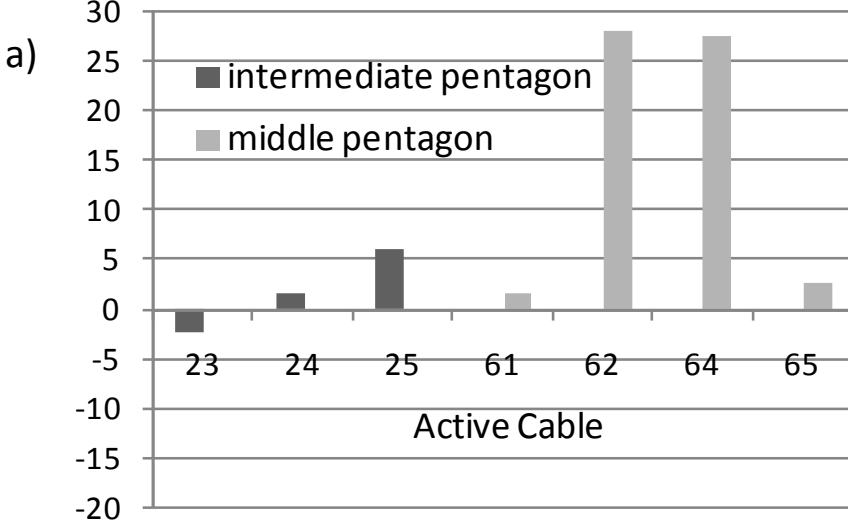

Preference Flow

b)

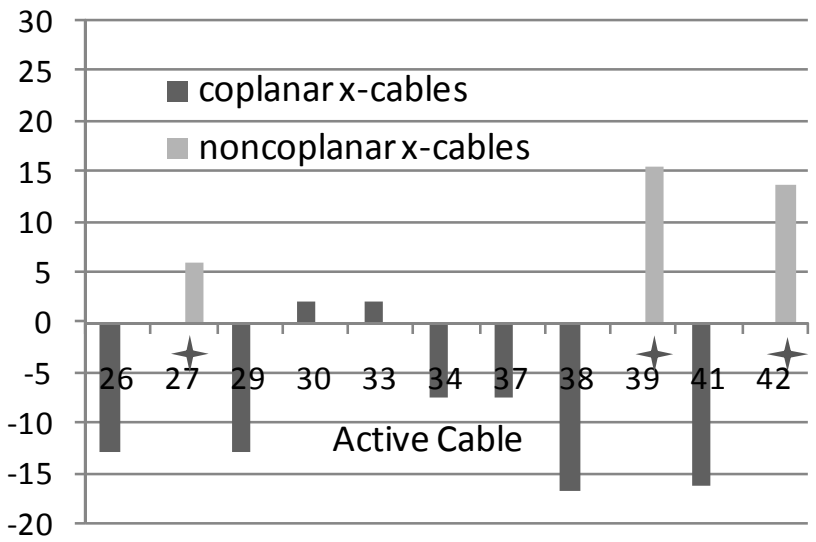

Preference Flow

c)

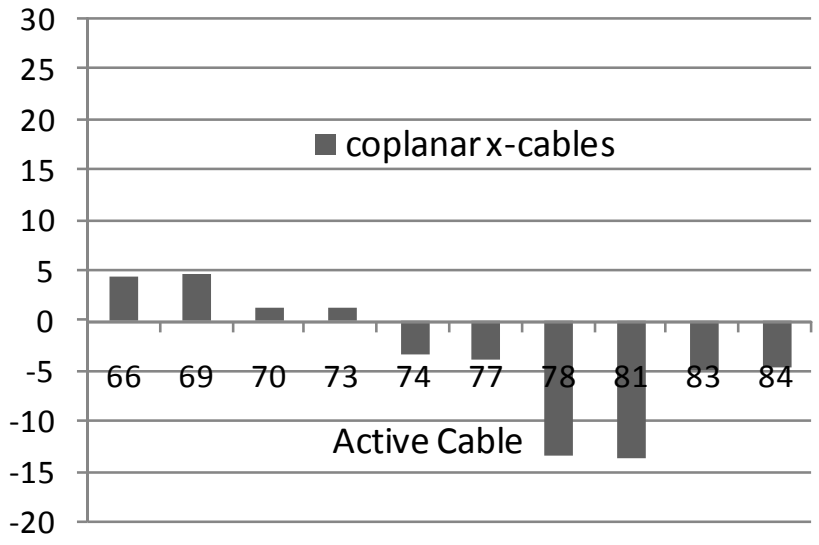

Figure 6. a. Preference flow values of the intermediate and middle pentagon layer cables b. Preference flow values of $x$-cables of the first module (continuous cables are indicated with four point stars)

c. Preference flow values of $x$-cables of the second module 
Korkmaz,S. Bel Hadl Ali, N. and Smith, I.F.C. "Configuration of control system for damage tolerance of a tensegrity bridge" Advanced Engineering Informatics, 26, 2012, pp 145-155 doi:10.1016/j.aei.2011.10.002

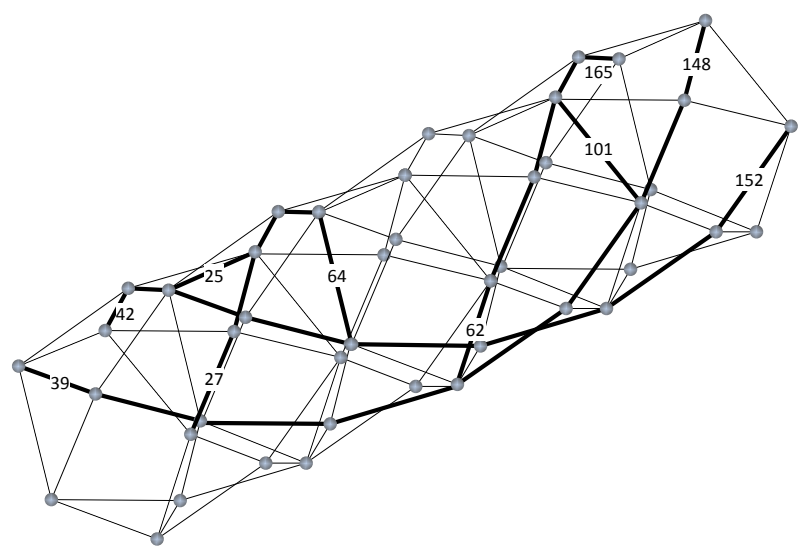

(a) The 10 most efficient cables

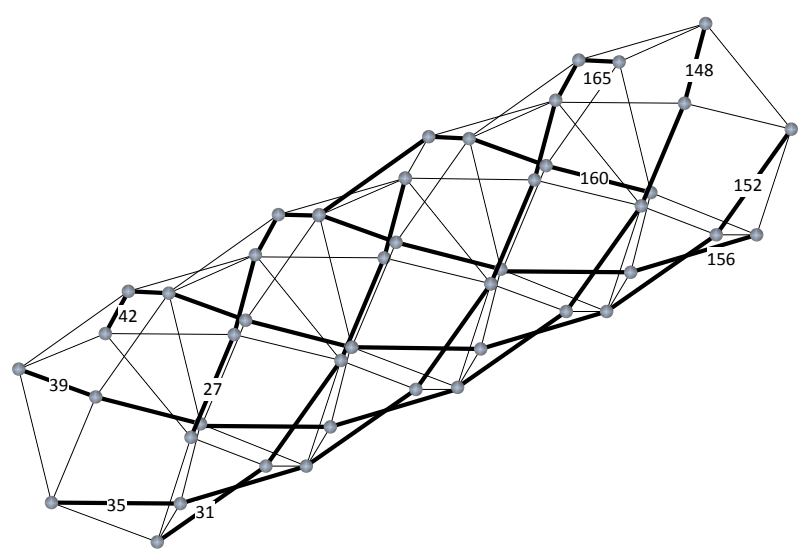

(b) The 10 cables required for deployment

Figure 7. Active cables employed for damage tolerance 
Korkmaz,S. Bel Hadl Ali, N. and Smith, I.F.C. "Configuration of control system for damage tolerance of a tensegrity bridge" Advanced Engineering Informatics, 26, 2012, pp 145-155 doi:10.1016/j.aei.2011.10.002

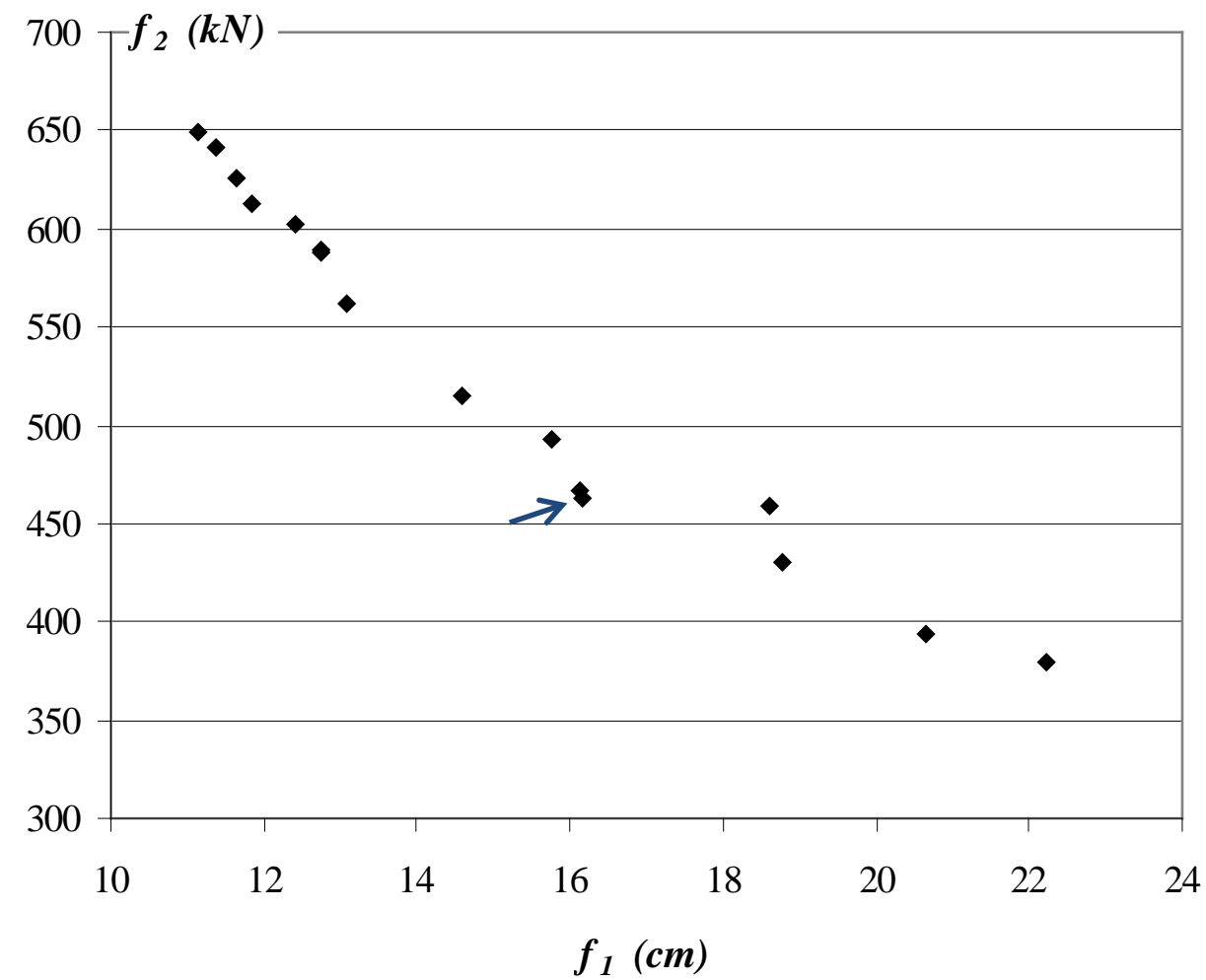

Figure 8. Pareto optimal solutions obtained with most efficient cables (Cable 42 damaged) 
Korkmaz,S. Bel Hadl Ali, N. and Smith, I.F.C. "Configuration of control system for damage tolerance of a tensegrity bridge" Advanced Engineering Informatics, 26, 2012, pp 145-155 doi:10.1016/j.aei.2011.10.002

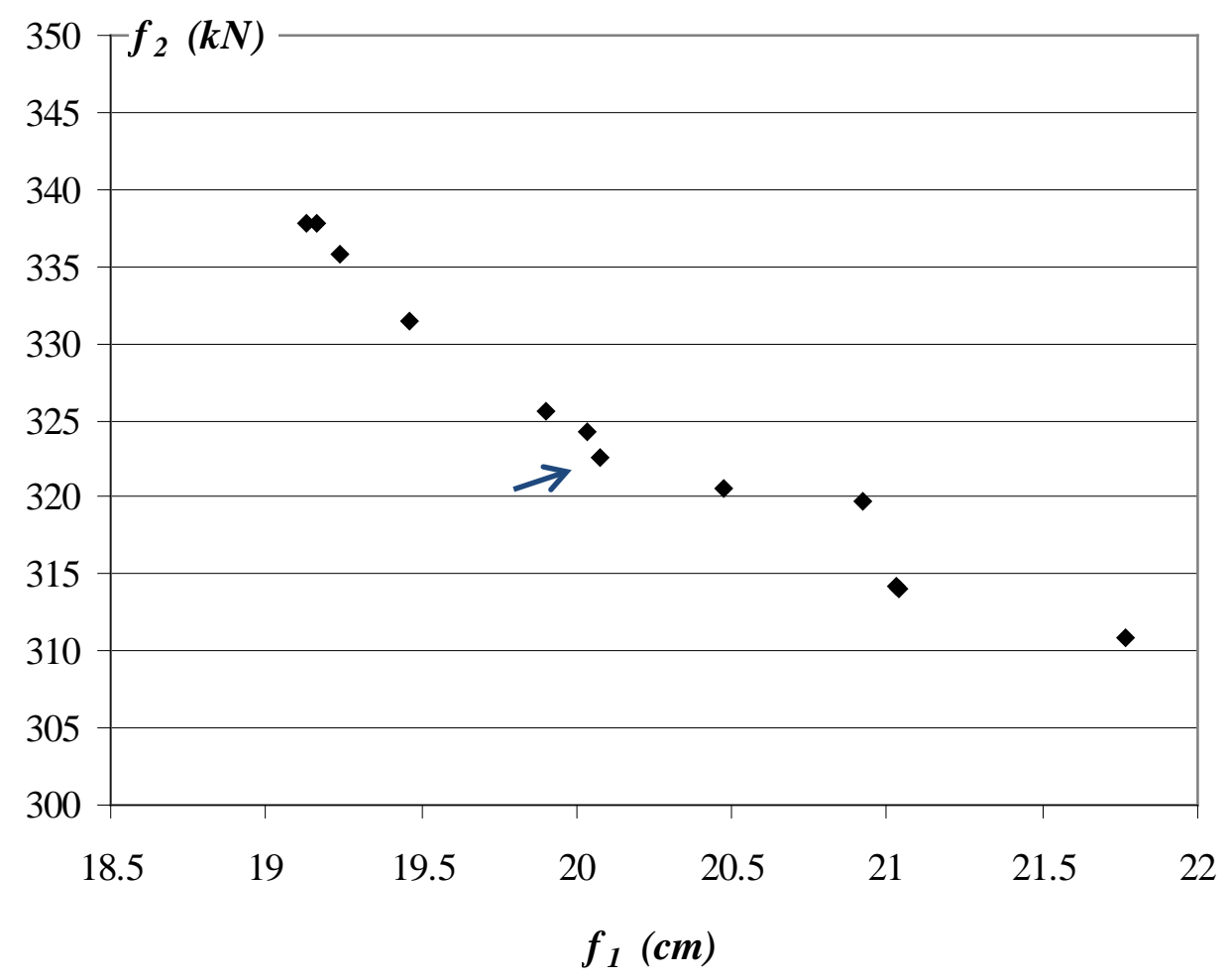

Figure 9. Pareto optimal solutions obtained with deployment cables (Cable 42 damaged)

This work is licensed under a Creative Commons Attribution-NonCommercial-NoDerivatives 4.0 International License

(c) (i) (9) 